\title{
PHÂN BỔ HợP LÝ TÀI NGUYÊN NƯỚC LƯU VỰC SÔNG SREPOK
}

\author{
Đỗ Thị Ngọc Bích ${ }^{1}$, Nguyễn Cao Đơnn",*
}

Tóm tắt: Lưu vục sông Srêpok là một trong nhũng lưu vực sông lớn của nước ta, có nguồn nước xuyên biên giới, do đó việc nghiên cứu phân bổ hợp lý tài nguyên nước luu vực sông Srepok nhằm bảo vệ tài nguyên và môi truờng mà vẫn đảm bảo cho việc phát triển kinh tếxã hội của các ngành địa phưong cần phải có những luận cứ thuyết phuc. Báo cáo này trình bày kết quả tính toán phân bổ nguồn nước cho các ngành ở nhũng vùng bị thiếu nước vào thời kỳ khô hạn sử dụng mô hình quy hoạch tuyến tính. Đầu vào của mô hình là giá trị kinh tế sủ dụng nước và nhu cầu nước cho các ngành trồng trọt, chăn nuôi, thủy sản, công nghiệp và sinh hoạt, kết hợp với với lượng nuớc có thể phân bổ cho tùng vùng theo các tháng trong điè̀u kiện chưa có các công trình tạo nguồn. Kết quả cho thấy, nhu cầu nước của cả lư vục chiếm 95\% là phục vu tưới cho nông nghiệp nhung giá trị kinh tế ngành này đem lại thấp hơn nhiều so với ngành chăn nuôi và công nghiệp. Bên cạnh đó, một số vùng bị thiếu nước nghiêm trọng vào mùa khô, lương nuớc chura đáp ứng được $10 \%$ nhu cầu. Do đó, ngoài uu tiên cấp đủ nước cho sinh hoạt thi các ngành công nghiệp, chăn nuôi, thủy sản cũng được ưu tiên cấp lượng nước tối thiểu đủ để duy trì sản xuất. Lượng nước tuới còn thiếu cần được quy hoạch cấp nước tù các hồ chứa nước hoạc chuyển nước tù các sông lân cận.

Từ khóa: Quy hoạch tuyến tính, ước tính giá trị kinh tế sử dụng nước, phân bổ tài nguyên nước, luu vục sông Srepok.

Ban Biên tập nhận bài: 12/05/2019 Ngày phản biện xong: 25/06/2019 Ngày đăng bài: 25/07/2019

\section{Mở đầu}

Ở nhiều lưu vực, quy hoạch phân bổ hiện nay phải đối mặt không những với các thách thức biến động nguồn nước tương lai mà còn phải tiến hành cải cách những cơ chế phân bổ không còn phù hợp trước đây. Phổ biến nhất là những yêu cầu liên quan đến cách thức tái phân bổ giúp chuyển nguồn nước sử dụng nước cho mục đích nông nghiệp hiện tại sang các mục đích phát triển đô thị và công nghiệp cho giá trị kinh tế cao hơn. Nhất là khi nguồn nước trở nên khan hiếm, việc xây dựng phương án phân bổ nhằm đảm bảo đầy đủ các tiêu chí công bằng, bình đẳng trong khai thác sử dụng không phải là vấn đề dễ khi thuyết phục các bên liên quan để đạt được sự đồng thuận nếu không có luận cứ thuyết phục. Khi đó phương án nào mang lại giá trị kinh tế sử dụng nước tốt nhất hoặc được xem là có thể chấp

IViện Khoa học Tài nguyên nước, Số 8 phố Pháo Đài Láng, Đống Đa, Hà Nội

Email:ncaodonwru@gmail.com nhận được sau khi đã cân nhắc các mặt lợi - thiệt về mặt kinh tế.

Trên thế giới hiện nay, đã có nhiều nghiên cứu về quy hoạch chia sẻ, phân bổ tài nguyên nước tiếp cận theo phương pháp dựa trên yếu tố kinh tế, điển hình như Han Yan và nnk (2011) đã nghiên cứu xây dựng mô hình quy hoạch tuyến tính đa mục tiêu áp dụng cho phân bổ tài nguyên nước cho thành phố Đại Liên (Trung Quốc) cho giai đoạn quy hoạch 2015 và 2020 . Kết quả của nghiên cứu đã cung cấp được công cụ hỗ trợ ra quyết định hữu ích cho các cơ quan quản lý tài nguyên nước khu vực này [6]. Ở Việt Nam, do những quy định về phân bổ tài nguyên nước mới được ban hành nên những nghiên cứu tương tự chưa được thực hiện nhiều. Viện Quy hoạch Thủy lợi (2000) đã thực hiện đề tài nghiên cứu tối ưu hóa trong quản lý, quy hoạch và khai thác tài nguyên nước với hàm mục tiêu về kinh 
tế trong sử dụng nước trên LVS Hồng - Thái Bình [5]. Luyện Đức Thuận (2013) đã ứng dụng quy hoạch tuyến tính trong bài toán phân bổ tài nguyên nước theo đơn vị hành chính, thí điểm cho tỉnh Hòa Bình [2]. Gần đây có nghiên cứu của Nguyễn Ngọc Hà (2018) ứng dụng phương pháp ước tính giá trị kinh tế sử dụng nước trong quy hoạch tài nguyên nước, áp dụng thử nghiệm cho lưu vực sông Vệ [3]. Tuy nhiên, trong các nghiên cứu đã và đang thực hiện, chưa có nghiên cứu phân bổ nào dựa trên giá trị kinh tế sử dụng nước và lý thuyết tối ưu cho lưu vực sông Srêpok. Nghiên cứu này sẽ là cơ sở cho việc đầu tư phát triển có định hướng các công trình tạo nguồn, bên cạnh đó, giá trị kinh tế sử dụng nước được tính toán cũng giúp cho việc đánh giá hiện trạng sử dụng nước của các ngành thông qua hiệu quả sử dụng nước.

\section{Dữ liệu và phương pháp nghiên cứu}

Các dữ liệu chính phục vụ nghiên cứu được thu thập, chọn lọc từ kết quả của một số công trình nghiên cứu trước đây như: dữ liệu về tổng lượng tài nguyên nước của lưu vực, dữ liệu về nhu cầu nước một số ngành chính, diện tích vùng tưới, số lượng gia súc gia cầm...Các dữ liệu sơ cấp nêu trên được nghiên cứu phân tích, đánh giá để làm đầu vào cho các tính toán tiếp theo như ước tính giá thị trường và chi phí của sản phẩm, tính toán nhu cầu nước của từng ngành theo tháng, lượng nước có thể phân bổ và lượng nước thiếu hụt. Các dữ liệu sau khi được nghiên cứu tính toán sẽ làm cơ sở cho việc tính toán phân bổ bằng phương pháp quy hoạch tuyến tính.

\begin{tabular}{|c|c|c|}
\hline $\begin{array}{l}\text { Giá trị } \\
\text { kinh tế sử } \\
\text { dụng nước } \\
\text { của các } \\
\text { ngành } \\
\text { dùng nước } \\
\text { chính }\end{array}$ & $\begin{array}{l}\text { Nhu cầu } \\
\text { nước theo } \\
\text { tháng của } \\
\text { các ngành } \\
\text { dùng } \\
\text { nước } \\
\text { chính }\end{array}$ & $\begin{array}{l}\text { Tổng } \\
\text { lượng } \\
\text { nước } \\
\text { có thể } \\
\text { phân } \\
\text { bổ theo } \\
\text { tháng }\end{array}$ \\
\hline \multicolumn{3}{|c|}{$\begin{array}{l}\text { Phân bổ lượng nước cho các ngành } \\
\text { dùng nước chính ở các vùng bị thiếu } \\
\text { nước vào mùa kiệt }\end{array}$} \\
\hline
\end{tabular}

Hình 1. So đồ nghiên cứu

\subsection{Giới thiệu luu vục sông Srepok}

LVS sông Srêpok trên lãnh thổ Việt Nam có diện tích tổng cộng là $30.100 \mathrm{~km}^{2}$, thuộc địa giới 4 tỉnh Gia Lai, Đăk lăk, Đăk Nông và Lâm Đồng.

\subsection{Phân chia tiểu vùng}

Vùng I: Vùng quy họach LV sông Ia Drăng chiếm toàn bộ TLV sông Ia Drăng với diện tích tổng cộng khoảng 1.028 km², dân số là 86.934 người, bao gồm một phần diện tích các $\mathrm{H}$. Đức Cơ, H. Chư Prông, H. Ia Grai và TP. Pleiku (tỉnh Gia Lai). Trong vùng hiện có 34 công trình thủy lợi gồm có 20 hồ chứa và 14 đập dâng, có tổng dung tích 13.306 nghìn $\mathrm{m}^{3}, 05$ công trình thủy điện.

Vùng II: Vùng quy họach LV sông Ia Lôp chiếm toàn bộ diện tích TLV sông Ia Lôp, diện tích tổng cộng $1.755 \mathrm{~km}^{2}$, dân số là 134.651 người, bao gồm một phần diện tích các huyện Chư Prông, Chư Sê, H. Chư Pưh (tỉnh Gia Lai) và $H$. Ea Soup (tỉnh Đăk Lăk). Trong vùng hiện có 37 công trình thủy lợi, trong đó có 16 hồ chứa, 18 đập dâng, 3 trạm bơm với tổng dung tích là 16.528 nghìn $\mathrm{m}^{3}$ và 1 thủy điện.

Vùng IIIa: Vùng quy họach Thượng lưu sông Ea H'Leo chiếm phần diện tích thượng lưu của TLV sông Ea H'Leo, mật độ dân số là 82 người $/ \mathrm{km}^{2}$, dân số là 207.448 người, có các khu độ thị như: TT. Ea Drăng (H. Ea H'Leo), TT. Ea Soup (H. Ea Soup) và Krông Buk (H. Krông Buk). Trong vùng hiện có 65 công trình với 61 hồ chứa, 4 đập dâng và 21 công trình thủy điện.

Vùng IIIb: Vùng quy họach Hạ lưu sông Ea H'Leo chiếm phần diện tích phía hạ lưu của TLV sông Ea H'Leo, diện tích tổng cộng khoảng 772 km2, dân số khoảng 22.721 người, bao gồm một phần diện tích H. Chư Prông (tỉnh Gia Lai) và các H. Ea Soup, H. Buôn Đôn (tỉnh Đăk Lăk). Trong vùng hiện có 8 công trình hồ chứa và có 1 trạm cấp nước tập trung.

Vùng IVa: Vùng quy họach thượng lưu sông Srêpok chiếm phần diện tích thượng lưu của TLV sông Srêpok, diện tích tổng cộng khoảng $2.518,7$ km², dân số là 670.296 người, gồm có các đô thị sau: TP. Buôn Mê Thuột, TT Quảng 
Phú (H. Cư M'Gar), TT. Ea Pôk (H. Cư M'Gar), TT. Buôn Đôn (H. Buôn Đôn), TT. Ea T’Ling (H. Cư Jút), TT. Đăk Mâm (H. Krông Nô), TT. Đức An (H. Đăk Song) và TT. Đăk Mil (H. Đăk Mil). Trong vùng hiện có 155 công trình với 126 hồ chứa, 29 đập dâng, trên dòng chính có 5 thủy điện lớn đó là thủy điện Buôn Kuôp, thủy điện Hòa Phú, thủy điện Dray Hlinh 1\&2, thủy điện Srêpok 3 và thủy điện Srêpok 4, 4A, ngoài ra còn có 15 công trình thủy điện vừa và nhỏ.

Vùng IVb: Vùng khai thác sử dụng hạ lưu sông Srêpok chiếm phần diện tích phía hạ lưu của TLV sông Srêpok, diện tích tổng cộng khoảng $1.688,3 \mathrm{~km}^{2}$, dân số khoảng 136.551 người, bao gồm 1 phần diện tích các $\mathrm{H}$. Đắk Mil, H. Cư Jút (tỉnh Đắk Nông) và 1 phần diện tích $H$. Buôn Đôn (tỉnh Đăk Lăk). Trên vùng hiện có 16 công trình với 13 hồ chứa, 3 đập dâng và 6 công trình thủy điện, trong đó có thủy điện Srêpok 4A lấy nước trực tiếp từ thủy điện Srêpok 4 qua kênh dẫn.

Vùng Va: Vùng quy họach Thượng lưu sông Ea Krông Ana chiếm phần diện tích thượng lưu của TLV sông Ea Krông Ana, diện tích tổng cộng khoảng $2.946,4 \mathrm{~km}^{2}$, dân số khoảng 498.037 người, bao gồm 1 phần diện tích các $H$. Krông Năng, H. Krông Buk, H. Ea Kar, H. Krông Păk, H. Ea Kar, H. M’Đrắk, H. Krông Bông, TX. Buôn Hồ (tỉnh Đăk Lăk). Trong vùnh hiện có 222 công trình với 181 hồ chứa, 18 đập dâng, 23 trạm bơm và 21 công trình thủy điện vừa và nhỏ.

Vùng Vb: Vùng quy họach Hạ lưu sông Ea Krông Ana bao gồm toàn diện tích phía hạ lưu của TLV sông Ea Krông Ana, diện tích tổng cộng khoảng $1.243,6 \mathrm{~km}^{2}$, dân số là 242.279 người, bao gồm 1 phần diện tích các $\mathrm{H}$. Lăk, $\mathrm{H}$. Krông Ana, H. Krông Bông, H. Krông Pắc, H. Cư Cư Kuin và H. Cư M'Gar (tỉnh Đăk Lăk). Trong vùng hiện có 152 công trình với 87 hồ chứa, 15 đập dâng, 27 trạm bơm và 12 công trình thủy điện vừa và nhỏ.

Vùng VIa: Vùng quy họach Thượng lưu sông Ea Krông Nô bao gồm toàn bộ diện tích thượng lưu của TLV sông Ea Krông Nô, diện tích tổng cộng khoảng $2.615,3 \mathrm{~km}^{2}$, dân số khoảng 100.211 người, bao gồm 1 phần diện tích các H. Lăk, H. Krông Bông (tỉnh Đăk Lăk), một phần diện tích các H. Đăk Glong, H. Krông Nô (tỉnh Đăk Nông) và 1 phần diện tích $H$. Đam Rông, H. Lạc Dương (tỉnh Lâm Đồng). Trong vùng hiện có 45 công trình với 28 hồ chứa, 15 đập dâng, 2 trạm bơm và 5 công trình thủy điện, trong đó có thủy điện Krông Nô 2, Krông Nô 3 nằm trên dòng chính sông $\mathrm{Ea}$ Krông Nô

Vùng VIb: Vùng quy họach Hạ lưu sông Ea Krông Nô bao gồm toàn bộ diện tích phần hạ lưu TLV sông Ea Krông Nô, diện tích tổng cộng khoảng $1.224,7 \mathrm{~km}^{2}$, dân số khoảng 84.390 người, bao gồm một phần diện tích các $\mathrm{H}$. Lăk, H. Krông Ana (tỉnh Đăk Lăk) và một phần diện tích các huyện $H$. Đắk Glong, H. Krông Nô, H. Đắk Song (tỉnh Đăk Nông). Trong vùng hiện có 16 công trình với 21 hồ chứa, 1 đập dâng, 3 trạm bơm và 5 công trình thủy điện, trong đó có thủy điện lớn Buôn Tua Srah nằm trên dòng chính sông Ea Krông Nô.

\subsection{Nguyên tắc phân bổ nguồn nước của} nghiên cúu

Hiện nay tại Việt Nam đa số mới chỉ ứng dụng một số mô hình như MIKE BASIN, WEAP...trong tính toán cân bằng nước làm cơ sở để phân bổ tài nguyên nước, chưa tính đến tối ưu lợi ích về mặt kinh tế và chưa được xem xét phân tích theo quan điểm của lý thuyết quy hoạch tuyến tính. Quan điểm này ưu tiên cấp nước theo hiệu quả kinh tế sử dụng nước cao nhất sau khi đã dành đủ lượng nước cho sinh hoat.

\section{Kết quả nghiên cứu}

3.1. Đánh giá nhu cầu nước của một số ngành dùng nước chính và lượng nước có thể phân bổ của lưu vục sông Srepok

Nghiên cứu chỉ tính toán bài toán hiện trạng, tức là chưa tính đến các công trình tạo nguồn, nhu cầu dùng nước thời đoạn tính toán chỉ tính đến năm 2020 và lượng nước có thể phân bổ ứng với tần suất nước đến $\mathrm{P}=85 \%$.

Từ số liệu thống kê thu được, nghiên cứu đã tính toán được nhu cầu nước của từng ngành của 
từng vùng trong năm. Có thể thấy rằng, do đặc thù chủ yếu là khu vực nông thôn miền núi, mật độ dân cư thấp, nền kinh tế chủ yếu dựa vào trồng trọt nên nhu cầu nước ngành trồng trọt chiếm $95,4 \%$ nhu cầu nước toàn nền kinh tế (Hình 2).

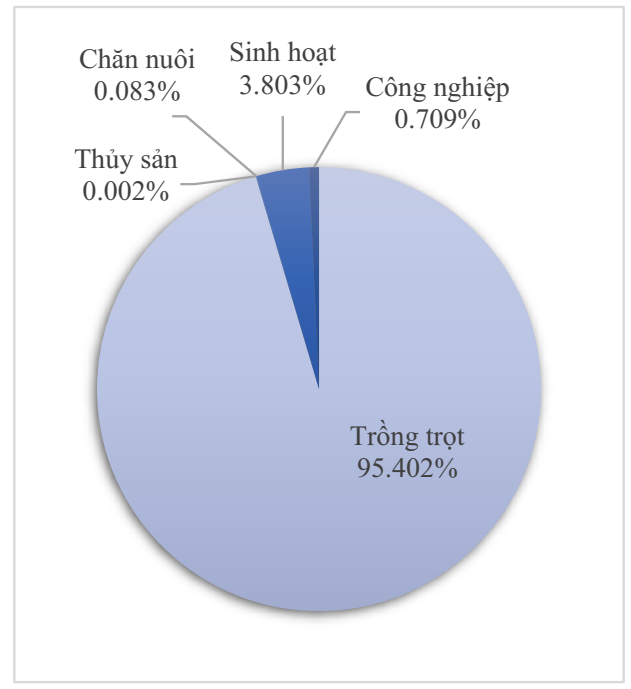

Hình 2. Tỷ lệ nhu cầu nuoóc các ngành toàn vùng thời kỳ 2020

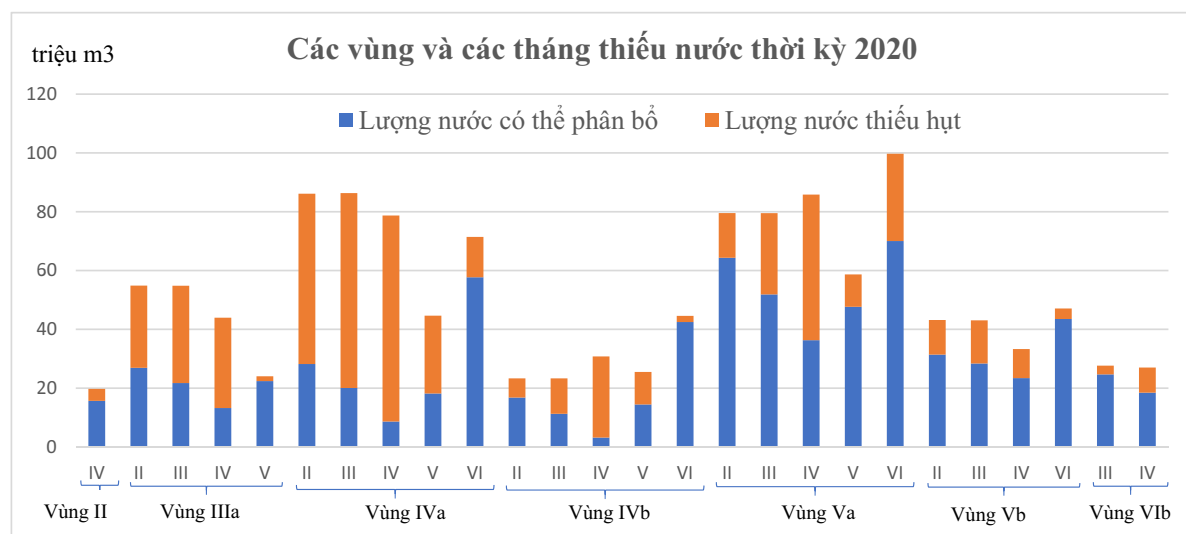

Hình 3. Các vùng và các tháng thiếu nước thời kỳ 2020

Lượng nước có thể sử dụng bao gồm lượng nước mặt và lượng nước dưới đất có thể khai thác ổn định. Lượng nước có thể phân bổ là lượng nước có thể sử dụng trừ đi lượng nước duy trì dòng chảy môi trường. Những tháng mùa kiệt ở một số vùng có nhu cầu sử dụng nước của các ngành cao hơn lượng nước có thể phân bổ sẽ dẫn đến thiếu hụt nguồn nước (Hình 3). Do đó, cần phải có phương án phân bổ hợp lý trong những thời điểm như vậy nhằm đảm bảo duy trì dòng chảy môi trường mà và nền kinh tế vẫn đạt hiệu quả sản suất cao nhất.

3.2. U'ớc tính giá trị kinh tế sử dụng nước của một số ngành dùng nước chính lưu vụcc sông Srepok
3.2.1. Uớc tính giá trị kinh tế sư dụng nước ngành nông nghiệp luu vục sông Srepok

Việc ước tính GTKTSDN ngành nông nghiệp bao gồm các nội dung sau:

1) Xác định giá trị sản xuất nông nghiệp

Là chỉ tiêu tổng hợp phản ánh kết quả hoạt động sản xuất kinh doanh ngành nông nghiệp dưới dạng sản phẩm vật chất và dịch vụ được quy về tiền (đồng) trong thời gian 1 năm.

Sản xuất nông nghiệp được xét trong đề tài bao gồm 3 ngành:

+ Trồng trọt: lúa (đông xuân, hè thu), hoa màu (ngô) và cây lâu năm (tiêu, điều, cà phê).

+ Chăn nuôi: Trâu, bò, lợn, gà, gia cầm, dê, cừu. 
+ Nuôi trồng thủy sản: Cá rô phi.

2) Xác định chi phí sản xuất nông nghiệp

Chi phí sản xuất nông nghiệp bao gồm: chi phí sản xuất theo từng ngành (chi phí nhân công, chi phí vật chất).

Chi phí sản xuất nông nghiệp được xác định theo Định mức kinh tế - kỹ thuật cây trồng vật nuôi chính do UBND các tỉnh thuộc lưu vực sông Srepok ban hành [4].

Chi phí vật chất là toàn bộ chi phí vật chất thực tế, hợp lý phát sinh trong một quá trình sản xuất bao gồm: giống, phân bón, thức ăn, thuốc bảo vệ thực vật, dụng cụ lao động...

Chi phí lao động gồm toàn bộ các chi phí tiền công lao động thực tế như với trồng lúa (làm đất, sửa bờ, gieo cấy, bón phân, làm cỏ, phun thuốc, gặt, vận chuyển, suốt lúa, phơi lúa...), trồng màu (phát bờ, bón lót, gieo hạt, bón phân, phun thuốc, thu hoạch, bốc xếp...), trồng cây lâu năm, chăn nuôi, nuôi trồng thủy sản.

3) Xác định lượng nước sủ dụng cho nông nghiệp.

Lượng nước sử dụng cho nông nghiệp được tính toán từ nhu cầu dùng nước cho nông nghiệp.

4) Ước tính giá trị kinh tế sủ dụng nước ngành nông nghiẹp.

Trên cơ sở xác định được giá trị sản xuất tại tiểu mục 1), chi phí sản xuất tại tiểu mục 2) và lượng nước sử dụng cho nông nghiệp, tiến hành ước tính giá trị kinh tế sử dụng nước ngành nông nghiệp theo phương pháp số dư (Residual Imputation Method - RIM) [1].

$\mathrm{P}_{\mathrm{w}}=\frac{\mathrm{TVP} \gamma-\left[\left(\mathrm{P}_{\mathrm{K}} * \mathrm{Q}_{\mathrm{K}}\right)+\left(\mathrm{P}_{\mathrm{L}} * \mathrm{Q}_{\mathrm{L}}\right)+\left(\mathrm{P}_{\mathrm{R}} * \mathrm{Q}_{\mathrm{R}}\right)\right]}{\mathrm{Q}_{\mathrm{w}}}$

Trong đó $\mathrm{TVP} \gamma$ là giá trị của tổng sản phẩm nông nghiệp (GTSP); (PK*QK) + (PL*QL) + $(\mathrm{PR} * \mathrm{QR})$ là tổng chi phí sản xuất nông nghiệp (CPSX); $\mathrm{PK}, \mathrm{QK}$ là giá trị vốn và số lượng ban đầu tham gia vào quá trình sản xuất ra tổng sản phẩm nông nghiệp; PL, QL là chi phí nhân công lao động và số nhân công lao động tham gia vào quá trình sản xuất ra tổng sản phẩm nông nghiệp; $\mathrm{PR}, \mathrm{QR}$ là chi phí tài nguyên và số lượng tài nguyên tham gia vào quá trình sản xuất ra tổng sản phẩm nông nghiệp; $\mathrm{QW}$ là lượng nước dùng tham gia vào quá trình sản xuất ra tổng sản phẩm nông nghiệp.

Kết quả tính toán giá trị kinh tế sử dụng nước ngành nông nghiệp lưu vực sông Srepok được trình bày trong các bảng dưới đây.

Bảng 1. Giá trị kinh tế nước cho ngành trồng trọt trên luu vục sông Srepok

\begin{tabular}{llrccr}
\hline $\begin{array}{c}\text { Lưu vực } \\
\text { sông }\end{array}$ & $\begin{array}{c}\text { Vùng quy } \\
\text { hoạch }\end{array}$ & $\begin{array}{c}\text { GTSP (triệu } \\
\text { đồng) }\end{array}$ & $\begin{array}{c}\text { CPSX (triệu } \\
\text { đồng) }\end{array}$ & $\begin{array}{c}\text { Lượng dùng } \\
\text { nước (triệu } \mathrm{m}^{3} \text { ) }\end{array}$ & $\begin{array}{c}\text { GTKTSDN } \\
\text { Tưới } \\
\text { (đồng/m }\end{array}$ \\
\hline Ia Drăng & Vùng I & 1.676 .627 & 1.337 .806 & 66,68 & 5.081 \\
Ia Lốp & Vùng II & 3.019 .689 & 2.379 .147 & 125,56 & 5.101 \\
Ea & Vùng IIIa & 7.498 .361 & 5.967 .639 & 282,95 & 5.410 \\
H’Leo & Vùng IIIb & 659.220 & 535.030 & 75,68 & 1.641 \\
Srêpok & Vùng IVa & 11.849 .650 & 9.458 .587 & 437,74 & 5.462 \\
Ea Krông & Vùng IVb & 3.995 .310 & 3.180 .054 & 163,65 & 4.982 \\
Ana & Vùng Va & 11.329 .667 & 9.071 .006 & 553,01 & 4.084 \\
Ea Krông & Vùng VIa & 5.412 .277 & 4.271 .402 & 282,59 & 4.037 \\
Nô & Vùng VIb & 3.695 .304 & 2.365 .441 & 135,89 & 3.899 \\
\hline
\end{tabular}


Bảng 2. Giá trị kinh tế nước cho ngành chăn nuôi trên lưu vục sông Srepok

\begin{tabular}{llcccc}
\hline $\begin{array}{c}\text { Lưu vực } \\
\text { sông }\end{array}$ & $\begin{array}{c}\text { Vùng quy } \\
\text { hoạch }\end{array}$ & $\begin{array}{c}\text { GTSP } \\
\text { (triệu đồng) }\end{array}$ & $\begin{array}{c}\text { CPSX (triệu } \\
\text { dồng) }\end{array}$ & $\begin{array}{c}\text { Lượng dùng } \\
\text { nước (triệu } \text { m}^{3} \text { ) }\end{array}$ & $\begin{array}{c}\text { GTKTSDN } \\
\text { Chăn nuôi } \\
\text { (đồng/m } / \mathrm{m}^{3}\end{array}$ \\
\hline Ia Drăng & Vùng I & 240.882 & 26.259 & 2,22 & 96.677 \\
Ia Lốp & Vùng II & 194.324 & 24.862 & 1,78 & 95.203 \\
Ea H’Leo & Vùng IIIa & 149.264 & 31.025 & 1,44 & 82.111 \\
& Vùng IIIb & 43.222 & 5.224 & 0,38 & 99.996 \\
Srêpok & Vùng IVa & 283.641 & 96.505 & 3,10 & 60.366 \\
Ea Krông & Vùng IVb & 91.059 & 22.343 & 0,91 & 75.511 \\
Ana & Vùng Va & 485.600 & 134.423 & 5,10 & 68.858 \\
Ea Krông & Vùng Vb & 208.803 & 59.452 & 2,21 & 67.580 \\
Nô & Vùng VIa & 73.578 & 15.449 & 0,72 & 80.734 \\
\hline
\end{tabular}

Bảng 3. Giá trị kinh tế nước cho ngành nuôi trông thủy sản trên lưu vục sông Srepok

\begin{tabular}{lccccc}
\hline $\begin{array}{c}\text { Lưu vực } \\
\text { sông }\end{array}$ & $\begin{array}{c}\text { Vùng quy } \\
\text { hoạch }\end{array}$ & $\begin{array}{c}\text { GTSP } \\
\text { (triệu đồng) }\end{array}$ & $\begin{array}{c}\text { CPSX (triệu } \\
\text { đồng) }\end{array}$ & $\begin{array}{c}\text { Lượng dùng } \\
\text { nước (triệu } \text { m}^{3} \text { ) }\end{array}$ & $\begin{array}{c}\text { GTKTSDN } \\
\text { NTTS } \\
\text { (đồng/m }\end{array}$ \\
\hline Ia Drăng & Vùng I & 119.000 & 111.860 & 0,92 & 7.761 \\
Ia Lốp & Vùng II & 242.500 & 227.950 & 2,41 & 6.037 \\
Ea & Vùng IIIa & 177.152 & 162.620 & 19,03 & 764 \\
H’Leo & Vùng IIIb & 61.952 & 56.870 & 11,23 & 453 \\
Srêpok & Vùng IVa & 482.304 & 442.740 & 31,02 & 1.275 \\
Ea & Vùng IVb & 158.720 & 145.700 & 4,94 & 2.636 \\
Krông & Vùng Va & 598.528 & 549.430 & 30,21 & 1.625 \\
Ana & Vùng Vb & 181.248 & 166.380 & 15,04 & 989 \\
Ea & Vùng VIa & 132.928 & 116.560 & 2,62 & 6.247 \\
Krông & Vùng VIb & 178.488 & 156.510 & 3,72 & 5.908 \\
Nô & & & & & \\
\hline
\end{tabular}

3.2.2. Ước tính giá trị kinh tế sử dụng nước ngành công nghiệp và cấp nước sinh hoạt luu vưc sông Srepok

Công nghiệp: Giá trị sản phẩm sử dụng nước với toàn ngành công nghiệp được tính toán bằng cách đánh giá tổng giá trị thu được của sản phẩm công nghiệp. Ước tính để làm ra 1 triệu đồng GDP ngành công nghiệp, cần sử dụng $25 \mathrm{~m}^{3}$ nước, như vậy giá trị trung bình của $1 \mathrm{~m} 3$ nước khoảng 109.000 đồng [2].

Sinh hoạt: Giá trị sử dụng nước sinh hoạt tương đương với giá nước sinh hoạt mà người dân sử dụng với lượng trung bình từ $10 \mathrm{~m}^{3}$ đến
$20 \mathrm{~m}^{3}$ một tháng của khu vực nghiên cứu, tức là khoảng 9.300 đồng $/ \mathrm{m}^{3}$.

\section{3. Ứng dụng quy hoạch tuyến tính đề xuất} phân bổ hợp lý tài nguyên nước lưu vục sông Srepok

3.3.1. Thiết lập bài toán quy hoạch tuyến tính trong phân bổ tài nguyên nước

Với mục tiêu lợi ích kinh tế từ việc sử dụng nước của các ngành là lớn nhất trên toàn lưu vực mà vẫn đảm bảo dòng chảy môi trường và nước sinh hoạt đầy đủ cho các hộ dân, bên cạnh đó các ngành dùng nước khác cũng có các điều kiện ràng buộc để đảm bảo duy trì sản xuất kinh 
doanh, nghiên cứu thiết lập hàm mục tiêu có dạng tuyến tính như sau:

$\mathrm{B}=\sum_{\text {dtưới tiêu. }} \mathrm{P}_{\text {tưới tiêu }}+\sum$ dcông nghiệp. $\mathrm{P}_{\text {công nghiệp }}+$ $\sum$ dchăn nuôi. $P_{\text {chăn nuôi }}+\sum_{\text {dthủy sản. }} \cdot \mathrm{P}_{\text {thủy sản }}+\sum_{\text {dsinh hoạt. }} \mathrm{P}_{\text {sinh }}$ hoạt

\section{$\mathrm{B} \rightarrow \mathrm{Max}$}

Trong đó $\mathrm{B}$ là tổng lợi ích kinh tế đạt được của các ngành dùng nước chính (hàm mục tiêu của bài toán); $\mathrm{d}_{\text {Tưới tiêu; }} \mathrm{d}_{\text {Công ngiệp }} ; \mathrm{d}_{\text {Chăn nuôi }} ; \mathrm{d}_{\text {Thủy sản }}$

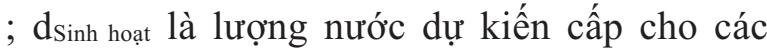
ngành dùng nước $\left(\mathrm{m}^{3}\right) ; \mathrm{P}_{\text {Tưới }}$; $\mathrm{P}_{\text {Công ngiệp }} ; \mathrm{P}_{\text {Chăn nuôii }}$;

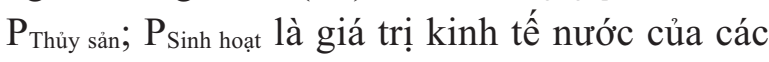
ngành dùng nước (nghìn $\mathrm{VNĐ} / \mathrm{m}^{3}$ ).

Ràng buộc về lượng nước được cấp

R1: $d_{\text {Sinh hoạt }}=100 \% * \mathrm{~W}_{\text {Sinh hoạt }}\left(\right.$ triệu m ${ }^{3}$ )

$\mathrm{R} 2$ : $\mathrm{d}_{\text {Công nghiệp }} \leq \mathrm{W}_{\text {công nghiệp }}$ (triệu $\mathrm{m}^{3}$ )

$\mathrm{R} 3: \mathrm{d}_{\text {Công nhiệp }} \geq 75 \% * \mathrm{~W}_{\text {công nghiệp }}\left(\right.$ triệu $\mathrm{m}^{3}$ )

R4: $\mathrm{d}_{\text {tưới tiêu }} \leq \mathrm{W}_{\text {tưới tiêu }}\left(\right.$ triệu $\mathrm{m}^{3}$ )

$\mathrm{R} 5: \mathrm{d}_{\text {tưới tiêu }} \geq 85 \% * \mathrm{~W}_{\text {tưới tiêu }}\left(\right.$ triệu $\mathrm{m}^{3}$ )

R6: $\mathrm{d}_{\text {chăn nuôi }} \leq \mathrm{W}_{\text {chăn nuôi }}$ (triệu $\mathrm{m}^{3}$ )

R7: $d_{\text {chăn nuôi }} \geq \% 75 \% * W_{\text {chăn nuôi }}$ (triệu $\mathrm{m}^{3}$ )

R8: $\mathrm{d}_{\text {thủy sản }} \leq \mathrm{W}_{\text {thủy sản }}\left(\right.$ triệu $\mathrm{m}^{3}$ )

$\mathrm{R} 9: \mathrm{d}_{\text {thủy sản }} \geq \% 80 \% * \mathrm{~W}_{\text {thủy sản }}\left(\right.$ triệu $\mathrm{m}^{3}$ )

Lượng nước cấp cho các ngành phải nhỏ hơn hoặc bằng tổng nhu cầu sử dụng nước của các ngành ( $\left.\mathrm{W}_{\text {ngành }}\right)$; Lượng nước cấp cho các ngành phải lớn hơn hoặc bằng $\%$ nhu cầu sử dụng nước của các ngành được cấp theo định hướng phát triển của tỉnh.

3.3.2. Xác định giải pháp phân bổ tài nguyên nuớc luu vục sông Srepok

Từ kết quả ước tính giá trị kinh tế sử dụng nước của các ngành dùng nước chính, sau khi ứng dụng phương pháp quy hoạch tuyến tính, nghiên cứu thu được kết quả được tổng hợp trong Bảng 4.

Vào các tháng cuối mùa khô (từ tháng II đến tháng VI) trùng với thời điểm tưới tập trung cho các vùng trồng tiêu, cà phê... người dân thường khai thác nước dưới đất để tưới cho cây trồng. Tuy nhiên, lượng nước dưới đất và nước mặt vào thời kỳ này cũng không đủ để cung cấp cho tưới tiêu, chính vì vậy, vai trò của các công trình hồ chứa và các công trình thủy lợi là hết sức quan trọng. Việc tính toán quy hoạch thiết kế các công trình tạo nguồn hợp lý sẽ giúp cải thiện tình trạng khô hạn vào mùa khô ở một số vùng thiếu nước nêu trên.

\section{Kết luận}

Lưu vực sông Srepok được chia thành 10 vùng từ Bắc xuống Nam, nhu cầu nước của cả lưu vực chiếm $95 \%$ là phục vụ tưới cho nông nghiệp. Tuy nhiên, có 7 vùng bị thiếu nước vào mùa kiệt (từ tháng II đến tháng VI), trong đó Vùng IVa và Vùng IVb bị thiếu nước nghiêm trọng vào tháng $\mathrm{IV}$, lượng nước còn lại cho tưới chưa đáp ứng được $10 \%$ nhu cầu. Kết quả ước tính giá trị kinh tế sử dụng nước của các ngành chính cho thấy, mặc dù nhu cầu tưới là cao nhất nhưng lại đem lại giá trị kinh tế thấp hơn nhiều so với ngành chăn nuôi và công nghiệp. Chính vì vậy, ngoài ưu tiên cấp đủ nước cho sinh hoạt thì các ngành công nghiệp, chăn nuôi, thủy sản cũng được ưu tiên cấp lượng nước tối thiểu đủ để duy trì sản xuất, lượng nước còn lại cấp cho tưới, nếu không đủ thì cần được quy hoạch cấp nước từ các hồ chứa nước hoặc chuyển nước từ các sông lân cận. Hạn chế của nghiên cứu là mới chỉ tính toán trong điều kiện bài toán hiện trạng và chưa tính đến các công trình tạo nguồn, nên kết quả nghiên cứu sẽ mang ý nghĩa tham khảo cho các quy hoạch tài nguyên nước và các công trình tạo nguồn nhằm khắc phục vấn đề thiếu hụt nguồn nước ở các vùng này. 
BÀI BÁO KHOA HỌC

Bảng 4. Lượng nước phân bổ cho các ngành đến năm 2020 chưa tính đến công trình tạo nguồn

\begin{tabular}{|c|c|c|c|c|c|c|c|c|c|c|c|c|}
\hline \multirow[b]{2}{*}{ Vùng } & \multirow[b]{2}{*}{ Tháng } & \multirow[b]{2}{*}{$\begin{array}{c}\text { Tổng } \\
\text { giá trị } \\
\text { kinh tế } \\
\text { đạt } \\
\text { được } \\
\text { (triệu } \\
\text { đồng) }\end{array}$} & \multicolumn{2}{|c|}{ Trồng trọt } & \multicolumn{2}{|c|}{ Thủy sản } & \multicolumn{2}{|c|}{ Chăn nuôi } & \multicolumn{2}{|c|}{ Sinh hoạt } & \multicolumn{2}{|c|}{ Công nghiệp } \\
\hline & & & $\begin{array}{c}\text { Lượng } \\
\text { nước } \\
\text { được } \\
\text { cấp } \\
\text { (triệu } \\
\mathrm{m}^{3} \text { ) }\end{array}$ & $\begin{array}{c}\text { \% đáp } \\
\text { úng } \\
\text { nhu } \\
\text { cầu }\end{array}$ & $\begin{array}{c}\text { Lượng } \\
\text { nước } \\
\text { được } \\
\text { cấp } \\
\text { (triệu } \\
\mathrm{m}^{3} \text { ) }\end{array}$ & $\begin{array}{c}\text { \% đáp } \\
\text { úng } \\
\text { nhu } \\
\text { cầu }\end{array}$ & $\begin{array}{c}\text { Lượng } \\
\text { nước } \\
\text { được } \\
\text { cấp } \\
\text { (triệu } \\
\mathrm{m}^{3} \text { ) }\end{array}$ & $\begin{array}{c}\% \\
\text { đáp } \\
\text { ứng } \\
\text { nhu } \\
\text { cầu }\end{array}$ & $\begin{array}{c}\text { Lượng } \\
\text { nước } \\
\text { được } \\
\text { cấp } \\
\text { (triệu } \\
\mathrm{m}^{3} \text { ) }\end{array}$ & $\begin{array}{c}\% \\
\text { đáp } \\
\text { ứng } \\
\text { nhu } \\
\text { cầu }\end{array}$ & $\begin{array}{c}\text { Lượng } \\
\text { nước } \\
\text { được } \\
\text { cấp } \\
\text { (triệu } \\
\mathrm{m}^{3} \text { ) }\end{array}$ & $\begin{array}{c}\text { \% đáp } \\
\text { ứng } \\
\text { nhu } \\
\text { cầu }\end{array}$ \\
\hline $\begin{array}{l}\text { Vùng } \\
\text { II }\end{array}$ & IV & 87.810 & 15,333 & $79 \%$ & 0,0008 & $80 \%$ & 0,015 & $75 \%$ & 0,304 & $100 \%$ & 0,007 & $75 \%$ \\
\hline Vùng & II & 159.692 & 25,922 & $48 \%$ & 0 & $\begin{array}{l}\text { Không } \\
\text { có nhu } \\
\text { cầu }\end{array}$ & 0,012 & $75 \%$ & 0,871 & $100 \%$ & 0,095 & $75 \%$ \\
\hline IIIa & III & 133.215 & 20,643 & $38 \%$ & 0,001 & $80 \%$ & 0,013 & $75 \%$ & 0,965 & $100 \%$ & 0,106 & $75 \%$ \\
\hline & IV & 86.649 & 12,164 & $28 \%$ & 0,001 & $80 \%$ & 0,012 & $75 \%$ & 0,934 & $100 \%$ & 0,102 & $75 \%$ \\
\hline & V & 140.734 & 21,258 & $30 \%$ & 0,001 & $80 \%$ & 0,017 & $75 \%$ & 0,965 & $100 \%$ & 0,141 & $75 \%$ \\
\hline & II & 247.515 & 24,570 & $30 \%$ & 0 & $\begin{array}{l}\text { Không } \\
\text { có nhu } \\
\text { cầu }\end{array}$ & 0,025 & $75 \%$ & 2,815 & $100 \%$ & 0,786 & $75 \%$ \\
\hline $\begin{array}{l}\text { Vung } \\
\text { IVa }\end{array}$ & III & 213.001 & 16,028 & $20 \%$ & 0,002 & $80 \%$ & 0,028 & $75 \%$ & 3,117 & $100 \%$ & 0,870 & $75 \%$ \\
\hline & IV & 147.400 & 4,759 & $6 \%$ & 0,002 & $80 \%$ & 0,027 & $75 \%$ & 3,016 & $100 \%$ & 0,842 & $75 \%$ \\
\hline & $\mathrm{V}$ & 202.813 & 14,163 & $35 \%$ & 0,002 & $80 \%$ & 0,028 & $75 \%$ & 3,117 & $100 \%$ & 0,870 & $75 \%$ \\
\hline & VI & 415.314 & 53,809 & $80 \%$ & 0,002 & $\begin{array}{c}80 \% \\
\text { Không }\end{array}$ & 0,027 & $75 \%$ & 3,016 & $100 \%$ & 0,842 & $75 \%$ \\
\hline & II & 87.196 & 16,211 & $71 \%$ & 0 & $\begin{array}{c}\text { có nhu } \\
\text { cầu }\end{array}$ & 0,007 & $75 \%$ & 0,574 & $100 \%$ & 0,005 & $75 \%$ \\
\hline Vung & III & 60.028 & 10,619 & $47 \%$ & 0,0005 & $80 \%$ & 0,008 & $75 \%$ & 0,635 & $100 \%$ & 0,006 & $75 \%$ \\
\hline & IV & 19.531 & 2,537 & $8,40 \%$ & 0,0005 & $80 \%$ & 0,008 & $75 \%$ & 0,614 & $100 \%$ & 0,005 & $75 \%$ \\
\hline & $\mathrm{V}$ & 75.875 & 13,800 & $56 \%$ & 0,0005 & $80 \%$ & 0,008 & $75 \%$ & 0,635 & $100 \%$ & 0,006 & $75 \%$ \\
\hline & VI & 215.721 & 41,838 & $95 \%$ & 0,0005 & $\begin{array}{c}80 \% \\
\text { Không }\end{array}$ & 0,010 & $75 \%$ & 0,614 & $100 \%$ & 0,007 & $75 \%$ \\
\hline & II & 305.654 & 61,918 & $80 \%$ & 0 & $\begin{array}{c}\text { có nhu } \\
\text { cầu }\end{array}$ & 0,041 & $75 \%$ & 2,092 & $100 \%$ & 0,280 & $75 \%$ \\
\hline Vùng & III & 259.360 & 49,198 & $64 \%$ & 0,002 & $80 \%$ & 0,045 & $75 \%$ & 2,316 & $100 \%$ & 0,310 & $75 \%$ \\
\hline & IV & 194.217 & 33,709 & $41 \%$ & 0,002 & $80 \%$ & 0,044 & $75 \%$ & 2,241 & $100 \%$ & 0,300 & $75 \%$ \\
\hline & $\mathrm{V}$ & 242.115 & 44,975 & $80 \%$ & 0,002 & $80 \%$ & 0,045 & $75 \%$ & 2,316 & $100 \%$ & 0,310 & $75 \%$ \\
\hline & VI & 331.898 & 67,421 & $70 \%$ & 0,002 & $80 \%$ & 0,044 & $75 \%$ & 2,241 & $100 \%$ & 0,300 & $75 \%$ \\
\hline Vùng & II & 158.918 & 35,759 & $85 \%$ & 0 & $\begin{array}{l}\text { Không } \\
\text { có nhu } \\
\text { cầu }\end{array}$ & 0,018 & $75 \%$ & 1,018 & $100 \%$ & 0,036 & $75 \%$ \\
\hline $\mathrm{Vb}$ & III & 125.884 & 27,189 & $65 \%$ & 0,0006 & $80 \%$ & 0,020 & $75 \%$ & 1,127 & $100 \%$ & 0,040 & $75 \%$ \\
\hline & IV & 105.466 & 22,261 & $69 \%$ & 0,0006 & $80 \%$ & 0,019 & $75 \%$ & 1,090 & $100 \%$ & 0,038 & $75 \%$ \\
\hline & VI & 188.357 & 42,343 & $92 \%$ & 0,0006 & $80 \%$ & 0,025 & $75 \%$ & 1,090 & $100 \%$ & 0,051 & $75 \%$ \\
\hline Vùng & III & 102.074 & 24,263 & $89 \%$ & 0,0006 & $80 \%$ & 0,007 & $75 \%$ & 0,392 & $100 \%$ & 0 & $\begin{array}{l}\text { Không } \\
\text { có nhu } \\
\text { cầu }\end{array}$ \\
\hline $\mathrm{VIb}$ & IV & 76.814 & 18,067 & $68 \%$ & 0,0005 & $80 \%$ & 0,005 & $75 \%$ & 0,380 & $100 \%$ & 0 & $\begin{array}{l}\text { Không } \\
\text { có nhu } \\
\text { cầu }\end{array}$ \\
\hline
\end{tabular}




\section{BÀI BÁO KHOA HỌC}

\section{Tài liệu tham khảo}

1. Briscoe, J. (2011), Water as an Economic Good: Old and New Concepts and Implications for, Harvard University, Cambridge, MA, USA.

2. Luyện Đức Thuận (2013), Nghiên cứu ưng dụng quy hoạch tuyến tính trong bài toán phân bổ tài nguyên nước theo đơn vị hành chính, thí điểm cho tỉnh Hòa Bình (Báo cáo đề tài cấp cơ sở của Trung tâm Quy hoạch và Điều tra Tài nguyên nước quốc gia).

3. Nguyễn Ngọc Hà (2018), Nghiên cưu phương pháp uoớc tính giá trị kinh tế sủ dụng nước trong quy hoạch tài nguyên nước, áp dụng thử nghiệm cho lưu vưc sông Vệ (Luận án Tiến sĩ).

4. Quyết định Số 38/2013/QĐ-UBND của UBND tỉnh Đăk Lăk ngày 17 tháng 12 năm 2013 về việc ban hành định mức kinh tế kỹ thuật một số cây trồng vật nuôi chính trong sản xuất nông nghiệp trên địa bàn tỉnh.

5. Viện Quy hoạch Thủy lợi (2000), Nghiên cưu tối ưu hóa trong quản lý, quy hoạch và khai thác tài nguyên nuoóc trên LVS Hồng - Thái Bình.

6. Yan Han, Yue-Fei Huang, Guang-Qian Wang, Imran Maqsood (2011), A Multi-objective Linear Programming Model with Interval Parameters for Water Resources Allocation in Dalian City, Water Resources Management: An International Journal, Published for the European Water Resources Association (EWRA), Springer; European Water Resources Association (EWRA), 25 (2), 449-463.

\section{WATER ALLOCATIONS IN THE SREPOK RIVER BASIN Do Thi Ngoc Bich", Nguyen Cao Don ${ }^{1, "}$ \\ ${ }^{1}$ Water Resources Institute, No.8 Phao Dai Lang Str., Dong Da, Hanoi}

Abstract: The Srepok River is one of the major rivers in Vietnam, with transboundary water resources, thus there must be convincing arguments for the water resources allocation in the Srepok River basin to protect resources and environment while ensuring socio-economic development. This paper presents the results of water allocations for different water sectors in the water shortage regions during droughts using a linear programming model. The inputs of the model are economic values of water use and water demand for different sectors such as agriculture, industry and domestic, combined with the amount of water that can be allocated to each region by months in the absence of water works. We found that 95\% of the basin's water demand is for irrigation, however, it brings in lower economic value than livestock and industry. Besides, in some regions being lack of water during droughts, the amount of water has not met 10\% of demand. Therefore, domestic, industry, livestock, and fisheries are given priority to supply a sufficient amount of water to sustain production. The insufficient amount of irrigation water should be planned to supply from reservoirs or transfer water from nearby rivers.

Keywords: Linear programming, economic value of water, water allocation, Srepok River basin. 